\title{
Well-being and the Great Recession in Spain
}

\author{
Jesús Peiró-Palomino \\ (Universitat Jaume I and INTECO Research Group, Spain) \\ Francesco Perugini \\ (Università Politecnica delle Marche, Italy) \\ Andrés J Picazo-Tadeo \\ (Universitat de València and INTECO Research Group, Spain) \\ Corresponding author: Andres.j.picazo@uv.es
}

\begin{abstract}
This letter assesses the impact of the Great Recession on well-being in Spanish provinces using two alternative composite indicators of objective well-being that include somewhat different dimensions. Whereas the crisis notably eroded economic well-being, its impact on overall well-being -which in addition to economic dimensions also includes non-economic ones- was imperceptible. This result points to the need to carefully define and assess well-being in empirical analyses.
\end{abstract}

Keywords: composite indicators; economic crisis; Spain; well-being.

JEL Classification: C61; I30.

\section{Introduction and motivation}

Assessing well-being is a challenging task. Whereas traditional measures have been based on simple economic indicators, mostly GDP per capita, society as a whole calls for a more comprehensive way to gauge well-being. In addition to economic issues, fresh measures should include other non-economic dimensions of well-being such as health, education or the environment, to name just a few. In response to this social demand, the Human Development Index was created by the United Nations in the 1990s, and included income per capita, education and life expectancy (see UN, 2016). Later on, the Commission on the Measurement of Economic Performance and Social Progress -launched in 2009 and headed up by the Nobel laureate Joseph Stiglitz- suggested several non-economic dimensions that, beyond economic ones, can affect well-being (Stiglitz et al., 2009). Furthermore, the OECD provides data at both national (Better Life Index dataset), and regional (OECD Regional Well-being Database) levels on these dimensions (see Durand, 2015).

Recently, several papers have employed these datasets to building objective composite indicators of well-being, mostly at the country level (e.g., Lorenz et al., 2017; Peiró-Palomino and Picazo-Tadeo, 2018). Nonetheless, the rankings of countries result- 
ing from these indicators are not significantly different from those derived from conventional measures of well-being, including GDP per capita. In addition, other recent research papers also conclude that there is a close relationship between subjective well-being and income (Stevenson and Wolfers, 2013).

According to the arguments outlined above, it might be sensible to assume that indicators based on economic dimensions such as GDP per capita are good proxies of overall well-being. However, in this letter we show that this might not be the case when it comes to assessing the impact of an economic crisis on well-being. In doing so, we empirically evaluate the impact of the Great Recession that began in 2008 (IMF, 2009; Camacho et al., 2018) on well-being in Spanish provinces, using two composite indicators of objective well-being computed with Data Envelopment Analysis (DEA) and Multi-Criteria-Decision-Making techniques (MCDM). One of them -referred to as economic well-being- just includes GDP per capita and the unemployment rate as essential economic dimensions of well-being, whereas the other -named overall wellbeing- also includes 5 non-economic dimensions. We find that: i) there are notable disparities in well-being across Spanish provinces; ii) when objective well-being is assessed only with economic dimensions a sharp decline is observed as a result of the Great Recession; conversely, when non-economic dimensions are also accounted for the decline is imperceptible. Accordingly, our conclusion is that the choice of wellbeing indicators should be carefully justified in empirical analyses.

\section{Data and methodology}

We employ information about 7 well-being dimensions at the level of the 50 Spanish provinces ${ }^{1}$, built with data from different sources for the period 2000-14 (Table 1). In constructing this dataset, we have attempted to catch a set of indicators as close as possible to those proposed by Stiglitz et al. (2009) and provided by the OECD at both national and regional levels, but using the much more limited information available for the Spanish provinces. Using these figures, we have computed averages for each indicator in the growth period 2000-07 and the crisis period 2008-14. To ensure comparability across dimensions, and given that the indicators have different measurement units, the data have been standardized on a 0-1 scale using the min-max method, with higher values representing better performance; minimum and maximum values are chosen from the whole 2000-14 period to ensure comparability over time. Finally, normalized data on dimensions have been used to build a couple of composite indicators of objective well-being: the first, economic well-being, includes only the

\footnotetext{
1 Spanish provinces correspond to NUTS 3 in the Eurostat nomenclature, while regions correspond to NUTS 2. The autonomous cities of Ceuta and Melilla have been excluded from the analysis.
} 
economic dimensions of income and jobs, while the other, overall well-being, considers all 7 dimensions.

\section{Table 1 here}

Regarding the methodology, we have used DEA and MCDM techniques as in PeiróPalomino and Picazo-Tadeo (2018). First, following Lovell et al. (1995) we have computed a composite well-being indicator for each province $p^{\prime}$ with DEA as:

Composite indicator $_{p^{\prime}}=$ Maximise $_{w_{d p}} \sum_{d=1}^{\mathrm{D}} w_{d p^{\prime}}$ dimension $_{d p^{\prime}}$

Subject to:

$$
\begin{array}{ll}
\sum_{d=1}^{D} w_{d p^{\prime}} \text { dimension }_{d p} \leq 1 & p=1, \ldots, 50 \\
w_{d p^{\prime}} \geq 0 & d=1, \ldots, \mathrm{D}
\end{array}
$$

where dimension $_{d p}$ is the observed value for dimension $d$ in province $p$, and $w_{d p}$ is the idiosyncratic weight assigned to dimension $d$ in the composite indicator of province $p$. Moreover, composite indicators from (1) are, by construction, bounded between zero and one, the latter representing highest-well being; i.e., the lower the score the smaller the well-being

Whereas DEA provides a successful approach to the building of a composite wellbeing indicator, it might be less effective when it comes to ranking provinces. In this respect, comparisons might be meaningless as provinces' well-being indicators are computed with different sets of weightings (Kao and Hung, 2005); besides, program (1) could assign a score of one -meaning highest well-being- to some provinces just because of lack of discriminating power (see technical details in Dyson et al., 2001). In order to ensure comparability and also increase the discriminating power, in a second stage we have employed MCDM techniques to compute a composite well-being indicator with common weights across provinces for dimensions, as proposed by Despotis (2002). Formally:

$$
\begin{array}{ll}
\text { Minimise }_{m_{d}, w_{d}, h} t \frac{1}{50} \sum_{p=1}^{50} m_{p}+(1-t) h & \\
\text { Subject to: } & \\
\quad \sum_{d=1}^{\mathrm{D}} w_{d} \text { dimension }_{d p}+m_{p}=\text { Composite indicator }_{p} & p=1, \ldots, 50 \\
\quad\left(m_{p}-h\right) \leq 0 & p=1, \ldots, 50 \\
m_{p} \geq 0 & p=1, \ldots, 50 \\
w_{d} \geq \varepsilon & d=1, \ldots, \mathrm{D} \\
h \geq 0 &
\end{array}
$$

where $w_{d}$ is the common weight assigned to dimension $d ; \varepsilon$ is a non-Archimedean small number; $h$ is a non-negative parameter to be estimated; $m_{p}$ represents the devi- 
ation between the composite indicator for province $p$ calculated with DEA, and that computed with MCDM; finally, $t$ is a parameter ranging from 0 to 1 , which we have set to 1 (see details in Peiró-Palomino and Picazo-Tadeo, 2018).

\section{Results and discussion}

Table 2 displays population-weighted averages for economic and overall well-being in both growth (2000-07) and crisis (2008-14) periods for provinces and regions; in this respect, as well-being affects people we have considered population-weighted averages to be much more illustrative than simple averages. ${ }^{2}$ Besides, Figure 1 illustrates the geographic distribution of well-being in Spain, with darker colours representing better performance. Overall well-being is unevenly distributed across space with no clear patterns, although the lowest scores are found in the Mediterranean coast and Southern provinces. Furthermore, it is observed a positive (although moderate) association between overall well-being and the level of development of provinces and regions -approached by real GDP per capita-, particularly in the recession period. ${ }^{3}$ Besides, lower economic well-being is found in Southern and Western provinces while Northern and Eastern provinces perform notably better. Lastly, intraregional heterogeneity is high in most cases, especially for overall well-being.

\section{Table 2 and Figure 1 here}

Generally speaking, the geographic patterns of well-being derived from our results are in line with those from other studies of well-being (or quality of life) in Spain carried out using different methodological approaches, aggregation levels and time periods. González et al. (2011; 2018) focused on quality of life at the municipal level, although they only considered a limited sample of municipalities and overlooked temporal variation. Murias et al. (2006) and Zarzosa and Somarriba (2013) examined well-being and social welfare, respectively, at the province (NUTS 3) level, also omitting temporal comparisons. Jurado and Pérez-Mayo (2012) elaborated a multidimensional well-being index for the Spanish regions (NUTS 2) with data for years 2000 and 2006. More recently, Herrero et al. (2018) also assessed well-being at the region level for the period 2006-2015, but they failed to provide a composite indicator.

Regarding the impact of the Great Recession, a severe deterioration is observed in all provinces between 2000-07 and 2008-14 when well-being is assessed considering only

\footnotetext{
${ }^{2}$ Provincial weights correspond to the share of the population in each province over total Spanish population in each period.

${ }^{3}$ For the case of provinces, Spearman rank correlation coefficients are statistically significant at standard confidence levels ( $p$-values are 0.095 and 0.002 for the growth and crisis periods, respectively).
} 
economic dimensions; e.g., population-weighted average economic well-being decreases from 0.809 to 0.439 . Conversely, well-being remains much more stable when it is assessed with our overall well-being indicator, with an average that even increases slightly from 0.747 to $0.792 ; 4$ These findings can be clearly seen in Figure 1, which also suggests that the geographical North-East versus South-West division observed in the growth years persisted during the crisis. Furthermore, the population-weighted distributions of overall well-being among Spanish provinces are not statistically different between 2000-07 and 2008-14 (Figure 2); conversely, those of economic well-being are statistically different; i.e., a notable shift to the left has occurred as result of the crisis.

Figure 2 here

\section{Conclusion}

In this note we report two main conclusions. First, the Great Recession has profoundly affected the economic dimensions of well-being in Spain, whereas the effect on overall well-being -which also includes other non-economic dimensions- has been negligible. Second, beyond the demand of academics, international organisations and society as a whole to broaden the notion of well-being, this concept needs to be carefully defined and assessed in empirical studies as different measures may lead to quite different interpretations.

\section{Acknowledgments}

We greatly acknowledge the comments and suggestions from two referees. The usual disclaimer applies.

\section{Disclosure statement}

No potential conflict of interest was reported by the authors.

\section{Funding}

This research has been supported by the European Regional Development Fund and the Spanish Agencia Estatal de Investigación (ECO2014-55221-P and ECO2016-75237-R); and the Valencian regional government (PROMETEOII/2014/053).

\footnotetext{
4 We have computed an additional well-being indicator excluding dimensions income and jobs from the overall indicator, showing that average non-economic well-being in the crisis $(0.800)$ is noticeably higher than in the preceding growth period (0.624). Results for this indicator at the province and region levels are available to readers on request.
} 


\section{References}

Camacho, M., Gadea, M.D., Pérez-Quirós, G., 2018. The Great Recession: The worst ever? Revista de Economía Aplicada 76, 73-100.

Despotis, D.K., 2002. Improving the discriminating power of DEA: Focus on globally efficient units. Journal of the Operational Research Society 53, 314-323.

Durand, M., 2015. The OECD Better Life initiative: How's life? and the measurement of well-being. Review of Income and Wealth 61(1), 4-17.

Dyson, R., Allen, R, Camanho, A., Podinovski, V., Sarrico, C., Shale, E., 2001. Pitfalls and protocols in DEA. European Journal of Operational Research 132, 245-259.

González, E., Cárcaba, A., Ventura, J., 2011. The importance of geographical level of analysis in the assessment of the quality of life: The case of Spain. Social Indicators Research 102, 209-228.

González, E., Cárcaba, A., Ventura, J., 2018. Weight constrained DEA measurement of the quality of fife in Spanish municipalities in 2011. Social Indicators Research $136,1157-1182$.

Herrero, C., Villar, A., Soler, A., 2018. Las facetas del bienestar: Una aproximación multidimensional a la calidad de vida en España y sus Comunidades Autónomas (2006-2015). Funcación BBVA.

IMF (International Monetary Fund), 2009. World Economic Outlook-April 2009: Crisis and recovery. Washington DC.

Jurado A., Perez-Mayo J., 2012. Construction and evolution of a multidimensional well-being index for the Spanish regions. Social Indicators Research 107, 259-279.

Kao, C., Hung, H.T., 2005. Data envelopment analysis with common weights: The compromise solution approach. Journal of the Operational Research Society 56, 1196-1203.

Lorenz, J., Brauer, C., Lorenz, D., 2017. Rank-optimal weighting or 'How to be best in the OECD Better Life Index?' Social Indicators Research, 134, 75-92.

Lovell, C.A.K., Pastor, J.T., Turner, J.A., 1995. Measuring macroeconomic performance in the OECD: A comparison of European and non-European countries. European Journal of Operations Research 87, 507-518.

Murias, P., Martinez, F., de Miguel, C., 2006. An economic wellbeing index for the Spanish provinces: A Data Envelopment Analysis approach. Social Indicators Research 77, 395-417.

Peiró-Palomino J., Picazo-Tadeo A.J., 2018. OECD: One or many? Ranking countries with a composite well-being indicator. Social Indicators Research, in press. 
Stevenson, B., Wolfers, J., 2013. Subjective well-being and income: Is there any evidence of satiation? American Economic Review: Papers \& Proceedings 103, 598604.

Stiglitz, J.E., Sen, A., Fitoussi, J.P., 2009. The measurement of economic performance and social progress revisited: Reflections and overview. Columbia University, IEP, OFCE Working Paper 2009-33.

UN (United Nations), 2016. Human Development Report 2016: Human development for everyone. United Nations Development Programme, New York.

Zarzosa Espina P., Somarriba Arechavala N., 2013. An assessment of social welfare in Spain: Territorial analysis using a synthetic welfare Indicator. Social Indicators Research 111, 1-23. 
Table 1. Well-being dimensions and indicators

\begin{tabular}{|c|c|c|c|}
\hline Dimension & Indicator (unit of measurement) & Source & Years \\
\hline Income & GDP per capita (constant $€$ at 2011 prices) & Spanish Statistical Office (INE) & $2002-2014$ \\
\hline Jobs & Unemployment rate $(\%)$ & INE & 2002-2014 \\
\hline Health & Life expectancy at birth (years); mortality rate $(\%)$ & INE & $2000-2014$ \\
\hline Education & Years of education (people aged 16-64) & Valencian Institute of Economic Research & $2000-2013$ \\
\hline Environment & Air particles PM10 (yearly average) & $\begin{array}{l}\text { Ecologistas en Acción, and Spanish Ministry of } \\
\text { Agriculture, Fishing and Environment }\end{array}$ & 2001-2014 \\
\hline Safety & Homicide rate (per 100,000 inhabitants) & Spanish Ministry of Home Affairs & 2000-2004; 2010-2014 \\
\hline Civic engagement & $\begin{array}{l}\text { Voter turnout in general elections to congress, } \\
\text { Spanish residents }(\%)\end{array}$ & Spanish Ministry of Home Affairs & $2000,2004,2008,2011$ \\
\hline
\end{tabular}

Note: The dimension health has been measured as the simple average of its two indicators. 
Table 2. Well-being scores: from 0 (worst) to 1 (best)

\begin{tabular}{|c|c|c|c|c|}
\hline \multirow{2}{*}{$\begin{array}{l}\text { Regions (NUTS 2) and their } \\
\text { provinces (NUTS 3) }\end{array}$} & \multicolumn{2}{|c|}{ Economic well-being } & \multicolumn{2}{|c|}{ Overall well-being } \\
\hline & $2000-07$ & 2008-14 & $2000-07$ & $2008-14$ \\
\hline Andalucía & 0.582 & 0.115 & 0.640 & 0.648 \\
\hline Almería & 0.789 & 0.080 & 0.668 & 0.654 \\
\hline Cádiz & 0.431 & 0.010 & 0.595 & 0.564 \\
\hline Córdoba & 0.505 & 0.114 & 0.727 & 0.738 \\
\hline Granada & 0.615 & 0.083 & 0.669 & 0.675 \\
\hline Huelva & 0.548 & 0.144 & 0.536 & 0.650 \\
\hline Jaén & 0.548 & 0.129 & 0.779 & 0.765 \\
\hline Málaga & 0.666 & 0.111 & 0.612 & 0.578 \\
\hline Sevilla & 0.583 & 0.203 & 0.609 & 0.670 \\
\hline Aragón & 0.966 & 0.618 & 0.864 & 0.895 \\
\hline Huesca & 0.989 & 0.721 & 0.938 & 0.970 \\
\hline Teruel & 1.000 & 0.677 & 1.000 & 0.949 \\
\hline Zaragoza & 0.955 & 0.585 & 0.826 & 0.870 \\
\hline Asturias & 0.797 & 0.539 & 0.823 & 0.816 \\
\hline Illes Balears & 0.899 & 0.495 & 0.569 & 0.665 \\
\hline Islas Canarias & 0.746 & 0.160 & 0.580 & 0.690 \\
\hline Las Palmas & 0.750 & 0.112 & 0.595 & 0.666 \\
\hline Santa Cruz de Tenerife & 0.741 & 0.212 & 0.563 & 0.715 \\
\hline Cantabria & 0.848 & 0.624 & 0.872 & 0.965 \\
\hline Castilla y León & 0.820 & 0.561 & 0.918 & 0.918 \\
\hline Ávila & 0.833 & 0.375 & 0.868 & 0.829 \\
\hline Burgos & 0.911 & 0.642 & 0.921 & 0.931 \\
\hline León & 0.810 & 0.512 & 0.882 & 0.841 \\
\hline Palencia & 0.885 & 0.572 & 0.881 & 0.889 \\
\hline Salamanca & 0.714 & 0.528 & 0.956 & 0.967 \\
\hline Segovia & 0.877 & 0.638 & 0.957 & 0.995 \\
\hline Soria & 0.982 & 0.708 & 0.988 & 0.952 \\
\hline Valladolid & 0.791 & 0.613 & 0.931 & 0.987 \\
\hline Zamora & 0.752 & 0.464 & 0.919 & 0.833 \\
\hline Castilla - La Mancha & 0.810 & 0.333 & 0.910 & 0.866 \\
\hline Albacete & 0.817 & 0.297 & 0.888 & 0.830 \\
\hline Ciudad Real & 0.777 & 0.279 & 0.822 & 0.821 \\
\hline Cuenca & 0.853 & 0.430 & 0.917 & 0.858 \\
\hline Guadalajara & 0.884 & 0.509 & 1.000 & 1.000 \\
\hline Toledo & 0.793 & 0.300 & 0.964 & 0.872 \\
\hline
\end{tabular}


Table 2. Well-being scores: from 0 (worst) to 1 (best) (Continued)

\begin{tabular}{|c|c|c|c|c|}
\hline \multirow{2}{*}{$\begin{array}{l}\text { Regions (NUTS 2) and their } \\
\text { provinces (NUTS 3) }\end{array}$} & \multicolumn{2}{|c|}{ Economic well-being } & \multicolumn{2}{|c|}{ Overall well-being } \\
\hline & $2000-07$ & $2008-14$ & $2000-07$ & 2008-14 \\
\hline Cataluña & 0.902 & 0.553 & 0.701 & 0.716 \\
\hline Barcelona & 0.890 & 0.556 & 0.709 & 0.712 \\
\hline Girona & 0.907 & 0.502 & 0.628 & 0.714 \\
\hline Lleida & 0.999 & 0.710 & 0.997 & 0.798 \\
\hline Tarragona & 0.932 & 0.496 & 0.545 & 0.703 \\
\hline Comunidad Valenciana & 0.808 & 0.351 & 0.649 & 0.755 \\
\hline Alicante & 0.769 & 0.311 & 0.613 & 0.751 \\
\hline Castellón & 0.928 & 0.350 & 0.764 & 0.781 \\
\hline Valencia & 0.809 & 0.380 & 0.649 & 0.753 \\
\hline Extremadura & 0.557 & 0.230 & 0.843 & 0.841 \\
\hline Badajoz & 0.532 & 0.195 & 0.820 & 0.807 \\
\hline Cáceres & 0.600 & 0.288 & 0.880 & 0.898 \\
\hline Galicia & 0.760 & 0.559 & 0.794 & 0.876 \\
\hline A Coruña & 0.748 & 0.611 & 0.790 & 0.890 \\
\hline Lugo & 0.858 & 0.675 & 0.684 & 0.875 \\
\hline Ourense & 0.795 & 0.553 & 0.843 & 0.832 \\
\hline Pontevedra & 0.724 & 0.457 & 0.824 & 0.874 \\
\hline Madrid & 0.971 & 0.658 & 0.794 & 0.915 \\
\hline Murcia & 0.809 & 0.330 & 0.812 & 0.844 \\
\hline Navarra & 1.000 & 0.735 & 1.000 & 1.000 \\
\hline País Vasco & 0.907 & 0.758 & 0.880 & 0.892 \\
\hline Álava & 0.952 & 0.787 & 0.969 & 0.960 \\
\hline Bizkaia & 0.848 & 0.704 & 0.823 & 0.840 \\
\hline Guipuzkoa & 0.984 & 0.834 & 0.933 & 0.946 \\
\hline La Rioja & 0.956 & 0.622 & 0.961 & 1.000 \\
\hline Population-weighted average & 0.809 & 0.439 & 0.747 & 0.792 \\
\hline Simple average & 0.807 & 0.449 & 0.806 & 0.828 \\
\hline Standard deviation & 0.144 & 0.220 & 0.144 & 0.118 \\
\hline
\end{tabular}

Note: Regions' averages are weighted by population; also note that some Spanish regions are single-province regions. 
Figure 1. Provincial distribution of economic and overall well-being in 2000-07 (top maps) and 2018-14 (bottom maps)

Economic well-being

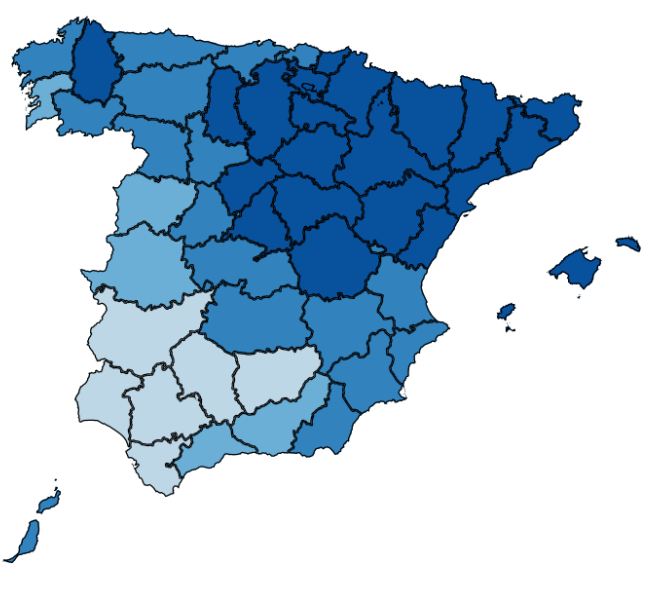

$\rightarrow 0 \rho^{8}$

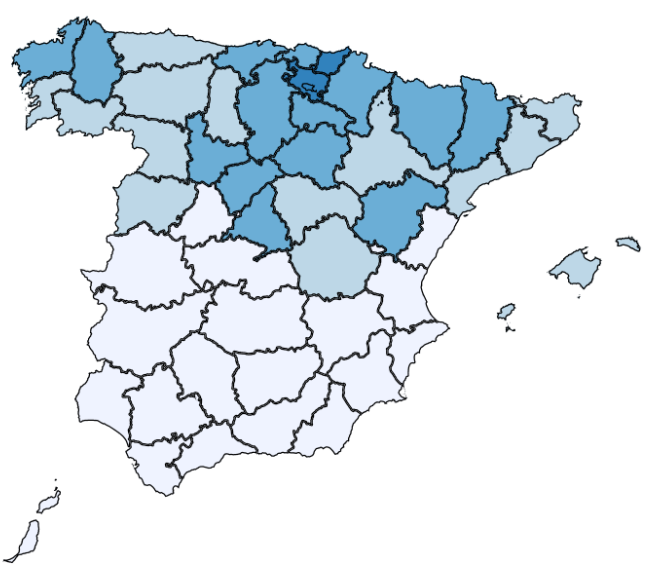

Overall well-being

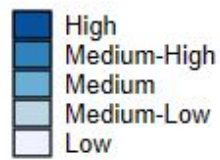

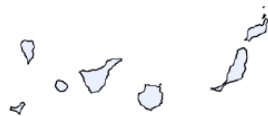

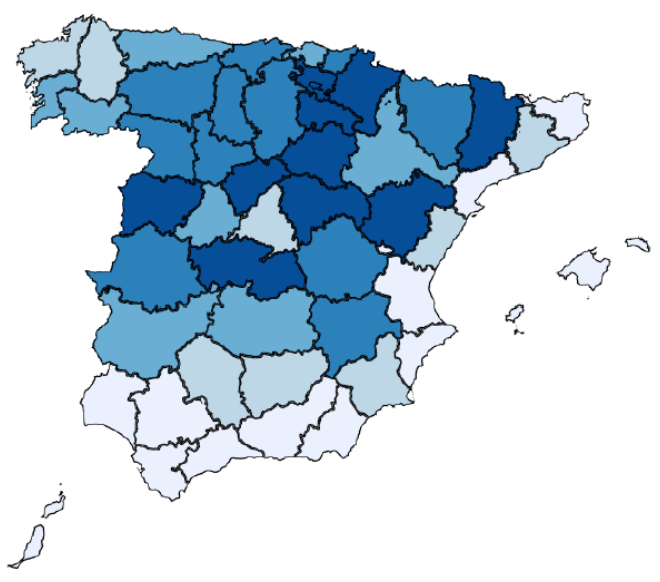

$\Delta \circ \nabla_{0}$

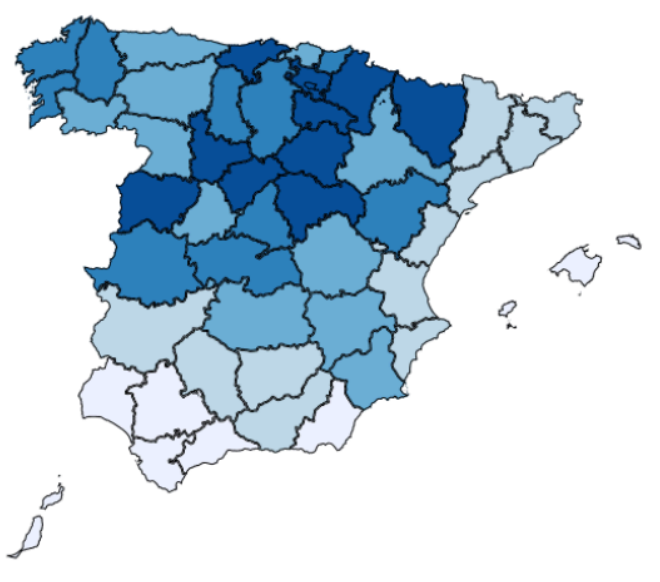

Note: Well-being is categorised through the distribution by quintiles of our composite indicators for the entire period, in order to evaluate disparities across regions and also over time. 
Figure 2. Population-weighted densities of economic and overall well-being for 2000-07 (solid lines) and 2008-14 (dashed lines)

Economic well-being

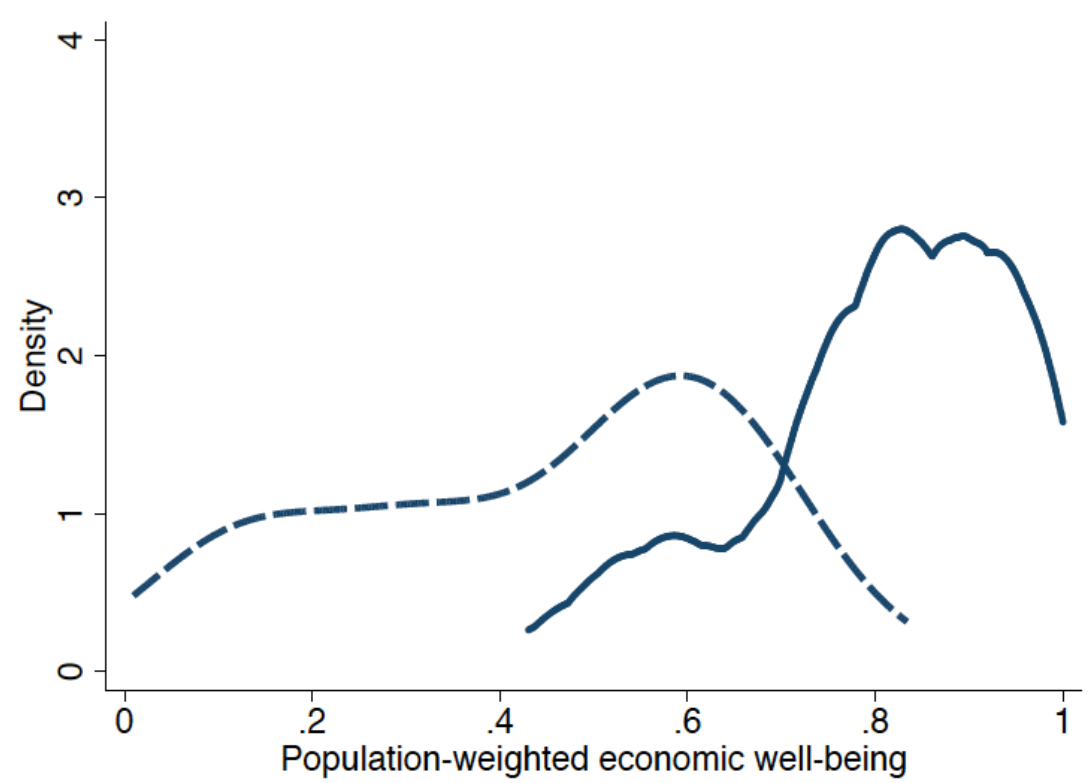

Overall well-being

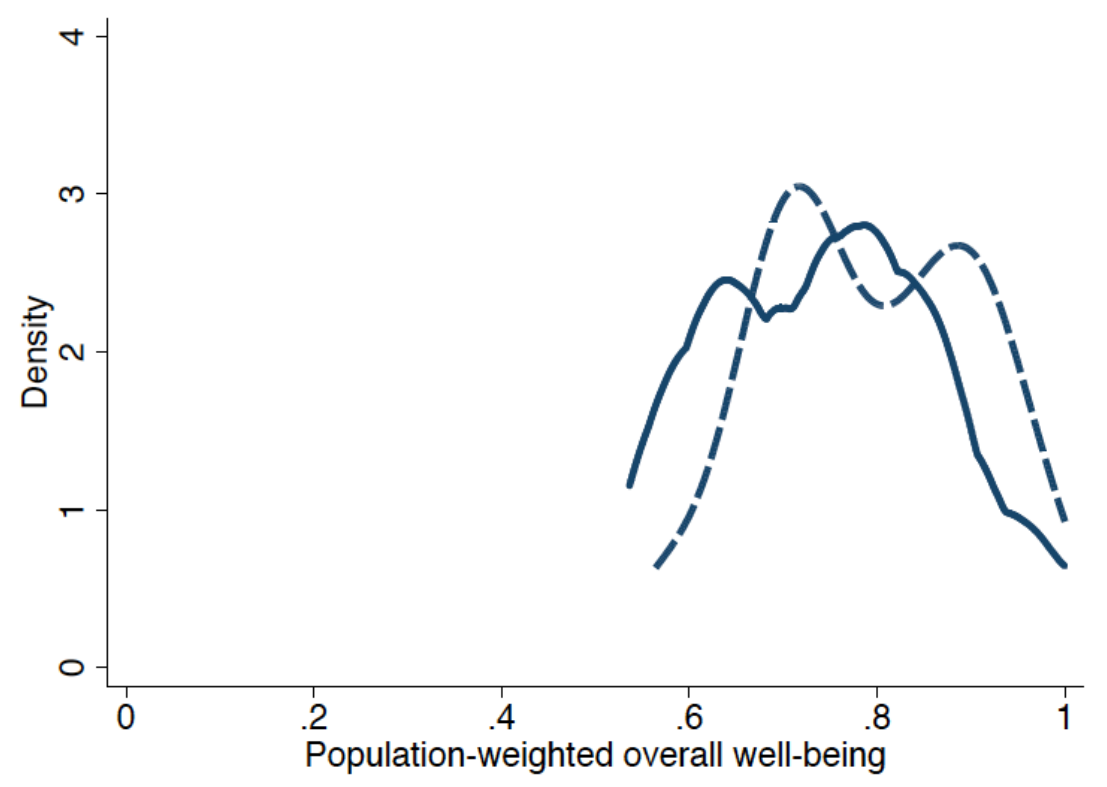

